\title{
Cross-Organizational Workflow Management Using Blockchain Technology - Towards Applicability, Auditability, and Automation
}

\author{
Gilbert Fridgen \\ Project Group Business \& Information Systems \\ Engineering of the Fraunhofer FIT \\ University of Bayreuth \\ gilbert.fridgen@uni-bayreuth.de \\ Sven Radszuwill \\ Project Group Business \& Information Systems \\ Engineering of the Fraunhofer FIT \\ University of Bayreuth \\ sven.radszuwill@fit.fraunhofer.de
}

\author{
Nils Urbach \\ Project Group Business \& Information Systems \\ Engineering of the Fraunhofer FIT \\ University of Bayreuth \\ nils.urbach@uni-bayreuth.de \\ Lena Utz \\ Project Group Business \& Information Systems \\ Engineering of the Fraunhofer FIT \\ University of Augsburg \\ lena.utz@fit.fraunhofer.de
}

\begin{abstract}
Bringing Blockchain technology and business process management together, we follow the Design Science Research approach and design, implement, and evaluate a Blockchain prototype for crossorganizational workflow management together with a German bank. For the use case of a documentary letter of credit we describe the status quo of the process, identify areas of improvement, implement a Blockchain solution, and compare both workflows. The prototype illustrates that the process, as of today paper-based and with high manual effort, can be significantly improved. Our research reveals that a tamper-proof process history for improved auditability, automation of manual process steps and the decentralized nature of the system can be major advantages of a Blockchain solution for crossorganizational workflow management. Further, our research provides insights how Blockchain technology can be used for business process management in general.
\end{abstract}

\section{Introduction}

In times of digital transformation, the evaluation of emerging technologies and identification of their potential application areas is of major importance to all organizations. Moreover, to remain competitive and transform their businesses, companies have to improve the supporting processes of their core business and become more efficient or even need to transform entire business models.

One type of support systems for business processes are workflow management systems (WfMSs) that coordinate work within the stages of business processes [29]. WfMSs became a standard solution in business process management (BPM) more than 20 years ago [15, 32]. Nowadays, in our globalized world it is not a new case that "business organizations often form a virtual enterprise with others to achieve various business goals" [13, p. 2]. It is not only necessary to have WfMSs in place within an organization, but also to extend WfMSs even beyond a company's boundaries to form cross-organizational WfMSs [13, 34]. Hereby, such cross-organizational workflows usually consist of intra- and inter-organizational workflows [39]. The integration of various participants and different intra-organizational WfMSs make cross-organizational WfMSs very complex [39, 41]. However, cross-organizational WfMSs can provide various benefits to the process participants such as greater transparency, increased integration, faster communication, and higher throughput [31]. The aforementioned aspects and the fact that workflows can be "distributed over a number of organizations" [34, p. 1] particularly align very well with the distributed nature of Blockchain technology. However, the restriction of current crossorganizational WfMSs often is that companies cannot agree on a central provider. Blockchain as a decentralized solution may overcome this problem.

The discussion about Blockchain as well as the technology itself has undergone a rapid development. Blockchain was originally only regarded as the technology behind Bitcoin. In recent years, huge potential for further application areas, particularly in the financial services sector, became apparent [2]. Financial institutions as well as start-ups are especially concerned with use cases that address financial transactions, shares, stock options or generally 
speaking the "trading of property rights" [2, p. 2]. Within this application area, Blockchain technology is already granted to be a real alternative to existing infrastructure [9]. However, Blockchain might also change various other areas of our daily routine [24] and a multitude of use cases from other application areas is already addressed, e.g. for supply chains [14, 18, 19], Internet of Things (IoT) security and privacy [6], or in the energy sector [21]. In the field of BPM, numerous applications seem possible in the future [19], for example "engineering applications in crossorganizational settings" [30, p. 1]. As Blockchain enables more efficient business collaboration, "it is crucial to develop approaches to identify existing collaboration processes" $[19$, p. 8] and thus improve collaboration using Blockchain technology. However, with Blockchain still being a fairly new technological concept, experiences with the development of Blockchain solutions are scarce.

In a joint effort with a German Bank, we aimed at developing a Blockchain prototype to improve a crossorganizational workflow. The use case we address is placed in the field of international trade finance, namely a documentary letter of credit. Here, the properties of Blockchain, such as a tamper-proof transaction history, a solution without a central authority and the possibility to integrate smart contracts to automatically check specific conditions and act accordingly, leave room for wide process and WfMS improvement. Hence, we pose the following research question:

RQ: Can Blockchain technology improve the cross-organizational workflow for a documentary letter of credit?

To answer the stated research question and develop the related Blockchain prototype, we follow the Design Science Research (DSR) approach [11, 12, 26]. We briefly explain the necessary foundations of cross-organizational WfMSs and Blockchain before we introduce our research approach. We use a documentary letter of credit as an example to develop and evaluate a Blockchain solution for the design of cross-organizational WfMSs. Based on the gained experience, we derive generalizable insights and give directions for future research in the field.

\section{Foundations}

In this section, we briefly describe the special characteristics of cross-organizational business processes and WfMSs as well as the foundations of Blockchain technology before bringing both concepts together. To not exceed the scope of this paper, we focus on relevant literature where necessary rather than providing an extensive overview.

\subsection{Cross-organizational workflow management}

Any workflow is case-based [35], thus WfMSs are concerned with specific cases that incorporate casespecific properties [39]. Nowadays, the increasing level of international cooperation "leads to the necessity of implementing interoperable software systems $[\ldots]$ of cross-organizational business processes" [42, p. 23]. Cross-organizational business processes are executed by different organizations whereas intra-organizational processes take place within one organization [42]. According to [27], crossorganizational workflows comprise three main characteristics. First, autonomic vs. collaborative: Collaborative enterprises should cooperate with each other on a workflow level but keep independent economic entities. Second, distributed vs. interrelated: Geographically distributed organizations need to be connected by joint workflows to realize the collaboration. Third, stable vs. dynamic: Crossorganizational workflows are rather dynamic compared to stable intra-organizational workflows. [27] Furthermore, [34] defines situations facilitating the use of cross-organizational workflows, thus WfMSs:

(a) "Capacity sharing: tasks are executed by external resources under the control of one workflow manager,

(b) Chained execution: the process is divided into subsequent phases and each business partner takes care of one phase,

(c) Subcontracting: a sub-process is executed by another organization,

(d) Case transfer: each partner uses the same workflow process and cases are transferred from one partner to another partner,

(e) Loosely coupled: each partner takes care of a specified part of the workflow process" [34].

We will argue in Section 4 that our specific use case, a documentary letter of credit, aligns well with the characteristics of [27] and can be classified within the categories (b) and (e) of [34].

\subsection{Blockchain}

Blockchain technology became known with the advent of the cryptocurrency Bitcoin [23] in 2009 and increasingly draws attention in both practice and research [9]. Blockchain is a decentralized data structure able to store transactions transparently, chronologically [28], and tamper-proof [1] in a distributed network. This technology consists of a chronologically ordered chain of blocks. Each block contains information about valid network activities since the last addition of the previous [28]. The link 
between the blocks is achieved via cryptographic hashes that connect block by block and thus build the chain. This approach ensures that transactions cannot be modified after data has been approved by all nodes. The Blockchain encompasses some important advantages by design. The most important are:

- Decentralization [4, 28]: As a decentralized solution, it does not require any third-party organization 'in the middle' to build trust.

- Data integrity and security: All data stored in the Blockchain is hard to revise or tamper with $[7,33]$.

- Transparency and auditability: The transactions conducted on the blockchain are transparent and allow for subsequent audits anytime [4].

- Automation: So called smart contracts are "selfexecuting scripts" [4, p. 2292], that can be stored and executed on certain types of Blockchain [28], e.g. on the Ethereum Blockchain. By using smart contracts, it is possible to incorporate exogenous effects or to check exogenous conditions. Checking the temperature of a trading good regularly and enforcing actions if it drops under a predefined level is one example how to use smart contracts.

Besides, there are other design parameters for Blockchain solutions. The most important ones are the differentiation between public and private [1] and between permission-less and permissioned. In a public Blockchain, anyone can take part whereas in a private Blockchain only certain parties can take part in the Blockchain network. A permission-less Blockchain allows anyone to approve new blocks, i.e. for mining, whereas in a permissioned Blockchain, only certain parties can approve new blocks.

Even though Blockchain gained prominence in 2009, scientists and industry executives are still at the beginning to fully understand its potential, especially from the perspective of technical challenges and limitations of the technology [2]. For example, [33] summarizes seven of the technology's challenges and limitations: throughput, latency, size and bandwidth, security, wasted resources, usability, and versioning, hard forks and multiple chains.

\subsection{Application of Blockchain technology}

Research focuses in over $80 \%$ on the Bitcoin system and deals in less than $20 \%$ with other Blockchain applications [40]. However, there are numerous applications available that go far beyond its first instantiation [2]. For example, Blockchain technology can be applied as marketplaces for financial assets or fraud-resistant supply chain records
[18] or it can create an environment for digital contracts and peer-to-peer data sharing in a cloud service [33]. From a researcher's point of view, scientific literature on Blockchain technology and business process management or workflow management is yet scarce. [20, p. 3] claim that "Blockchain technology has the potential to significantly change a wide spectrum of business processes" and [37] provide an idea on how Blockchain can maintain trust in a choreography of processes without a central authority [37]. The authors state that their approach can provide "an automatic and immutable transaction history", "direct implementation of the mediator process control logic" (using smart contracts), and "an audit trail for the complete collaborative business processes" [37, p. 2]. With these properties being desirable in many crossorganizational processes, we make use of them when describing the design of our prototype.

With Blockchain being a distributed system that is usually not operated by one particular party, it can be regarded as a sort of common infrastructure shared between all participants. This implies, that a crossorganizational WfMS based on Blockchain has one major advantage: cross-organizational workflows are enabled without the need for one particular authority. Hence, the use of a Blockchain-based system as an infrastructure between many organizations facilitates the automation and simplification of workflows that have not been taken into account for automation by single organizations before. On the downside, such a Blockchain-based solution may face challenges public goods are usually prone to, such as overuse, unclear responsibilities, or different opinions of users. Examples can already be observed in practice as the discussion on how to develop the Bitcoin Blockchain further is controversial [5].

We will discuss how this applies for our use case in more detail after having introduced all relevant information on the design of our prototype.

\section{Method}

For the development of the Blockchain-based crossorganizational WfMS we follow the design science research approach $[16,17,25,36]$. In general, DSR aims at solving identified organizational problems in a build-and-evaluate process, producing purposeful IT artifacts [12]. These design artifact is both "useful and fundamental in understanding that problem" [11]. DSR artifacts can be distinguished between constructs, models, methods, and instantiations, such as prototypes [16]. The building and application of an artifact should provide knowledge and understanding of the design problem as well as be generalizable and 
therefore applicable to similar settings [11]. To achieve this objective, we draw from experienced peculiarities whilst developing our solution and derive generalizable insights from the artifact evaluation. In particular, we address the organizational research problems by developing and evaluating an instantiation of a Blockchain-based crossorganizational WfMS. According to the widely accepted research approach by [26], the DSR process consists of six steps: problem identification and motivation, definition of the objectives for a solution, design and development, demonstration, evaluation, and communication (Figure 1).

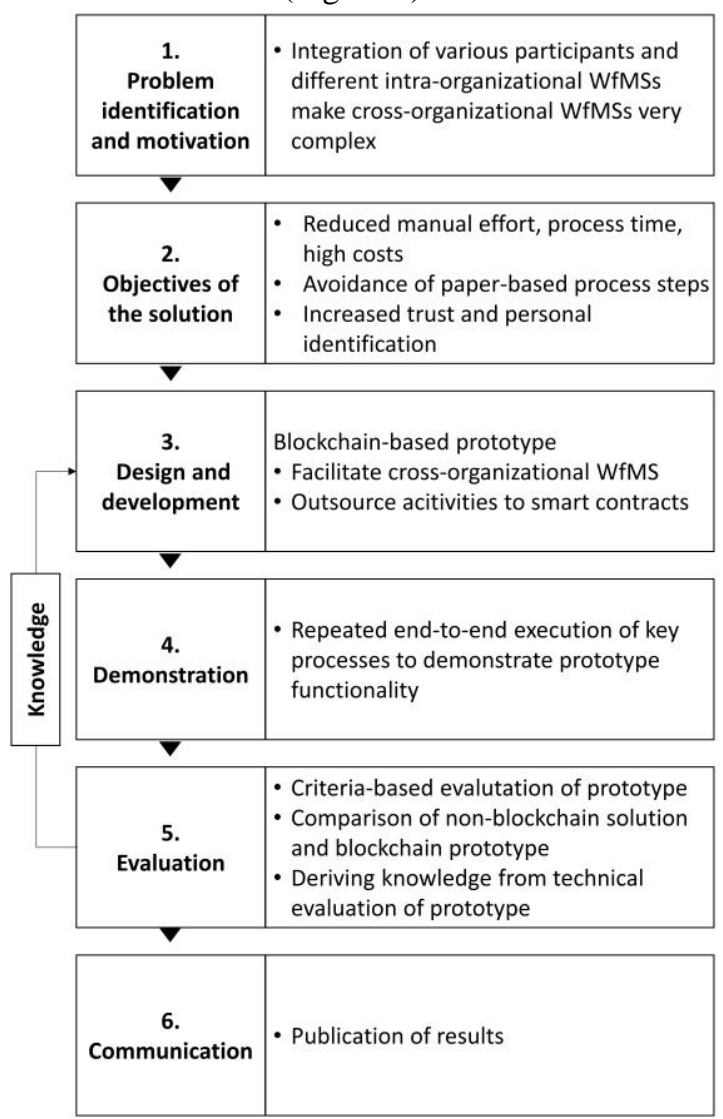

Figure 1. Applied Design Science Research Approach based on [26]

Our research starts with the identification and description of a problem of practical relevance [12]. As one example for a cross-organizational workflow, we analyze the current state of a documentary letter of credit (Section 4). In step 2, we derive objectives that a solution has to fulfill to resolve the identified issues. Accordingly, we define objectives that a Blockchainbased WfMS prototype should achieve. In step 3, we use these objectives as starting point for the design and development stage and define the required design attributes and build an instantiation of our Blockchainbased cross-organizational WfMS. In the research process, the design science steps "Design and Development", "Demonstration" and "Evaluation" are applied in an iterative and partly overlapping manner [3]. In step 4, we repeatedly conduct an end-to-end execution and testing of core processes to ensure and verify the functionality of the prototype. In step 5 , we link our prototype back to the determined evaluation criteria and conduct a comparison between the current non-Blockchain solution and our prototype. We evaluate using the areas of improvement and discuss to what extend the Blockchain solution can enhance the process. For that purpose, we conducted four semistructured interviews [22] with the main stakeholders of the bank involved. This approach allows us to gather feedback from experts on both, the application of Blockchain in the financial industry and on the process perspective of a letter of credit. Our interviews mostly consisted of open questions to allow for an open discussion of all aspects. Exemplary questions were: From your perspective, did the use of blockchain technology improve the process speed? What are the major advantages/disadvantages of the prototype compared to the status quo? What issues remain to be addressed in the future? As all participants were already familiar with the topic and the prototype, we gave a short introduction on our research before we discussed the areas of improvement (see Table 2) in detail. All experts were interviewed in May or June 2017, each interview lasting 30 to 45 minutes. We recorded the interviews and analyzed them afterwards, i.e. at least two researchers repeatedly scanned the interviews to identify the most important statements and interview outcome.

Table 1. Details on the semi-structured expert interviews

\begin{tabular}{lll}
\hline$\#$ & $\begin{array}{l}\text { Role of the } \\
\text { interviewee }\end{array}$ & $\begin{array}{l}\text { Involvement in } \\
\text { development process }\end{array}$ \\
\hline 1 & $\begin{array}{l}\text { Director in the } \\
\text { strategy department }\end{array}$ & Fully involved \\
\hline 2 & $\begin{array}{l}\text { Software architect; IT } \\
\text { innovation manager }\end{array}$ & Fully involved \\
\hline 3 & $\begin{array}{l}\text { Head of department } \\
\text { for international } \\
\text { payment transactions }\end{array}$ & $\begin{array}{l}\text { Partly involved, contact } \\
\text { person for international } \\
\text { payment (obligations) }\end{array}$ \\
\hline 4 & $\begin{array}{l}\text { Group leader and } \\
\text { expert for payment } \\
\text { obligations }\end{array}$ & $\begin{array}{l}\text { Partly involved, contact } \\
\text { person and process expert } \\
\text { for payment obligations }\end{array}$ \\
\hline
\end{tabular}

Finally, we outline the results of the evaluation as well as research and practical implications in the discussion section.

\section{Problem identification}

By successfully implementing WfMSs, companies can substantially improve the performance of their 
processes [26]. Furthermore, connecting crossorganizational business processes can be beneficial to organizations in various ways [39]. An example of such a business process is a documentary letter of credit, which is a payment instrument between trade partners in import/export business. It is offered by banks to their customers, usually companies actively conducting international trade. A letter of credit secures payment when certain conditions, particularly specific documents submitted correctly, have been met. A detailed explanation of the entire process of a letter of credit can e.g. be found in [10]. We focus on the central workflow within this process, namely the processing of all relevant documents. This workflow is crucial for this type of payment instrument because payment obligations are bound to the documents only, not to the trading goods. We depict the process of the document workflow (DW) in Figure 2.

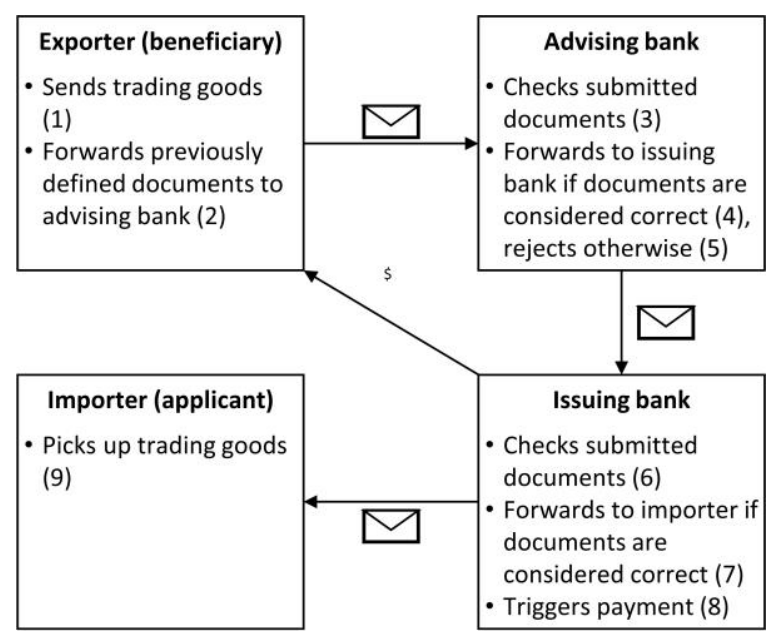

Figure 1. Schematic document workflow (DW) for a letter of credit

In general, the DW process involves four parties: an importer (applicant), an exporter (beneficiary) and two banks (advising bank and issuing bank). The procedure is supposed to avoid fraud and ensure payment. However, in its current version the DW is bulky and slow. The process runs as follows: The exporter sends the trading goods, e.g. by ship, to the importer (1) and submits all documents (2) to the advising bank (also called seller's bank). The advising bank then checks the documents (3) and forwards them to the issuing bank (also called buyer's bank), if they meet the predefined criteria (4). The issuing bank performs the tasks (6) and (7) analogously. In case both banks consider the documents to be submitted correctly, the issuing bank triggers the payment of the trading goods (8). The importer can now pick up the trading goods (9), e.g. in the harbor. In its current version, the process works by sending (by courier service) and manually processing a pile of paper-based documents from one process participant to the other. Hereby, paper-based documents in multiple versions must literally be send around the world. This process usually needs several days to finish, sometimes even longer than the actual shipping. According to this process, our use case is subdivided in four sub steps (one for each process participant) and is conducted step-by-step. Thus, it fits perfectly in the aforementioned categories of [34] for crossorganizational workflows: (b) chained execution and (e) loosely coupled and aligns well with the characteristics of [27]. Further, insights from the development of a Blockchain solution for this use case can serve as the basis for other Blockchain-based workflows in the future. The current state of the DW includes various possibilities for improvement which we address by developing a Blockchain prototype for the document workflow (BDW). We summarize the nine main areas of improvement in Table 2 . We evaluate our prototype (BDW) as to whether the improvements could have been (partly) put into place by the use of Blockchain technology.

Table 2. Areas of improvement - status quo

\begin{tabular}{|c|c|}
\hline $\begin{array}{l}\text { Area of } \\
\text { improvement } \\
\left(A I_{i}\right) \\
\end{array}$ & Description of status quo (DW) \\
\hline $\begin{array}{l}\boldsymbol{A I}_{\mathbf{1}}: \text { Processing } \\
\text { medium }\end{array}$ & $\begin{array}{l}\text { Paper-based: Almost all process } \\
\text { steps are conducted paper-based. For } \\
\text { security reasons, usually three or } \\
\text { more originals of each document are } \\
\text { used, i.e. are individually sent, } \\
\text { signed and processed. }\end{array}$ \\
\hline $\begin{array}{l}\mathrm{AI}_{2}: \text { Document } \\
\text { processing }\end{array}$ & $\begin{array}{l}\text { High manual effort: All document } \\
\text { auditing processes of both banks are } \\
\text { conducted manually. That implies } \\
\text { the audit of multiple versions of the } \\
\text { same document (multiple originals). }\end{array}$ \\
\hline $\begin{array}{l}\mathrm{AI}_{3}: \text { Processing } \\
\text { mode }\end{array}$ & $\begin{array}{l}\text { Sequential: The entire process must } \\
\text { be conducted step-by-step as the } \\
\text { original, paper-based documents are } \\
\text { needed for each step. }\end{array}$ \\
\hline $\begin{array}{l}\mathrm{AI}_{4}: \text { Process } \\
\text { tracking }\end{array}$ & $\begin{array}{l}\text { No (overall) tracking system: The } \\
\text { tracking of the DW is hardly } \\
\text { possible or done by direct } \\
\text { communication between the process } \\
\text { participants. }\end{array}$ \\
\hline $\begin{array}{l}\boldsymbol{A I}_{\mathbf{5}}: \text { Process } \\
\text { history }\end{array}$ & $\begin{array}{l}\text { No overall process history: If at all, } \\
\text { the process steps are recorded for } \\
\text { each participant individually. }\end{array}$ \\
\hline $\begin{array}{l}\text { AI }_{\mathbf{6}}: \text { Trust and } \\
\text { identification }\end{array}$ & $\begin{array}{l}\text { Opaque process participants: No } \\
\text { overview on the people involved is } \\
\text { present. For example, to get the } \\
\text { trading goods in the harbor, the } \\
\text { importer's representative must } \\
\text { provide specific documents and } \\
\text { proof of personal identification. }\end{array}$ \\
\hline
\end{tabular}




\begin{tabular}{ll}
\hline $\boldsymbol{A I}_{\mathbf{7}}$ : Process & $\begin{array}{l}\text { Overall time of several days: Most } \\
\text { of the time is needed for the sending } \\
\text { process (days) but also the manual } \\
\text { auditing process is time consuming. }\end{array}$ \\
\hline $\begin{array}{l}\boldsymbol{A I}_{\mathbf{8}} \text { : Process } \\
\text { flexibility }\end{array}$ & $\begin{array}{l}\text { Flexible under all circumstances: } \\
\text { Because of a high percentage of } \\
\text { customizable process steps the DW } \\
\text { can process all contract conditions }\end{array}$ \\
\hline $\boldsymbol{A I}_{\mathbf{9}}:$ Costs & $\begin{array}{l}\text { High costs: Due to long process time } \\
\text { and high manual effort the overall } \\
\text { costs are high }\end{array}$ \\
\hline
\end{tabular}

From the areas of improvement of the current DW $\left(A I_{i}\right)$, we derive concrete design objectives $\left(D O_{i}\right)$ for our prototype and summarize those in Table 3.

\section{Table 3. Design objectives for the Blockchain prototype}

\begin{tabular}{|c|c|}
\hline Design Objective $\left(D O_{i}\right)$ & Description of objective \\
\hline $\begin{array}{l}\boldsymbol{D O}_{1 \boldsymbol{1}}: \text { Digitize paper- } \\
\text { based process steps, e.g. } \\
\text { document sending }\end{array}$ & $\begin{array}{l}\text { The BDW maps a fully } \\
\text { digitized process, i.e. no } \\
\text { paper-based documents are } \\
\text { necessary. }\end{array}$ \\
\hline $\begin{array}{l}\mathbf{D O}_{1 b}: \text { Avoid multiple } \\
\text { originals and signatures }\end{array}$ & $\begin{array}{l}\text { By the use of digital } \\
\text { documents multiple } \\
\text { versions and signatures of } \\
\text { one document are not } \\
\text { required anymore. }\end{array}$ \\
\hline $\begin{array}{l}\mathbf{D O}_{2}: \text { Automate manual } \\
\text { document checking }\end{array}$ & $\begin{array}{l}\text { For the banks, the manual } \\
\text { document check is avoided } \\
\text { by the use of smart } \\
\text { contracts. }\end{array}$ \\
\hline $\begin{array}{l}\mathrm{DO}_{3}: \text { Allow for } \\
\text { concurrent document } \\
\text { processing }\end{array}$ & $\begin{array}{l}\text { As process participants do } \\
\text { not need to wait for paper- } \\
\text { based documents to arrive, } \\
\text { a concurrent document } \\
\text { check is possible for the } \\
\text { advising and issuing bank. }\end{array}$ \\
\hline $\begin{array}{l}\text { DO }_{4}: \text { Impose an overall } \\
\text { tracking system }\end{array}$ & $\begin{array}{l}\text { A real time process tracking } \\
\text { is implemented. }\end{array}$ \\
\hline $\begin{array}{l}\mathrm{DO}_{\mathbf{5}}: \text { Provide process } \\
\text { history }\end{array}$ & $\begin{array}{l}\text { Any process can be traced } \\
\text { end to end anytime. }\end{array}$ \\
\hline $\begin{array}{l}\mathbf{D O}_{6}: \text { Make process } \\
\text { participants (persons) } \\
\text { transparent }\end{array}$ & $\begin{array}{l}\text { Each participant must } \\
\text { identify before conducting } \\
\text { an action. }\end{array}$ \\
\hline $\begin{array}{l}\text { DO }_{7}: \text { Shorten overall } \\
\text { process time }\end{array}$ & $\begin{array}{l}\text { The overall process time is } \\
\text { heavily shortened. }\end{array}$ \\
\hline $\mathbf{D O}_{\mathbf{8}}:$ Keep high flexibility & $\begin{array}{l}\text { The DBW is applicable in } \\
\text { various situations, e.g. for } \\
\text { companies from different } \\
\text { countries, various document } \\
\text { requirements etc. }\end{array}$ \\
\hline $\mathrm{DO}_{9}:$ Lower Costs & $\begin{array}{l}\text { Overall, the BDW safes } \\
\text { costs. }\end{array}$ \\
\hline
\end{tabular}

\section{Development}

Using the design objectives, we iteratively designed and developed the BDW and the prototype accordingly. We implemented the prototype using a private Ethereum Blockchain (ETH) [38] as it allows, as one major and current Blockchain technology, for the use of smart contracts. Hereby, we put ourselves mostly in the place of the issuing bank and simulate the other process participants, i.e. we did not include real world participants other than the issuing bank. We point out that this was not a question of feasibility but only of practicability for the prototype implementation. The prototype is designed, implemented and can be used by several participants. For the BDW, we outline the changes compared to the original process steps (1) - (9) in the following:

(1) We do not alter the sending of trading goods, but we assume that all documents are available in digital form or can be digitized before step (2) and implement the prototype accordingly $\left(\mathrm{DO}_{1 a}\right)$. For example, we assume the so-called bill of lading and corresponding documents to be signed digitally using mobile devices.

(2) The exporter forwards all necessary documents in digital form to the advising bank. To assure for auditability, all information in each document is stored permanently and tamper-proof into the Blockchain. Therewith, the sending of multiple copies of a document can be avoided $\left(D O_{1 b}\right)$. Further, by providing the documents in digital form concurrent document checking $\left(\mathrm{DO}_{3}\right)$ by both banks is made feasible.

(3) We divide the checking process in two parts. On the one hand, we implement all conditions that can be checked automatically using smart contracts $\left(\mathrm{DO}_{2}\right)$. For example, it may be specified that the sending of the trading goods must be accomplished before a certain date, say June $15^{\text {th }}$ 2017, 11:59pm HST. Thus, a smart contract checks if all documents have been signed before this date. Depending on the document format, the same logic is applied for other conditions as well. We depict such conditions exemplarily in Figure 3 . On the other hand, there are conditions that cannot be implemented for automated checking as they need human expertise and experience, e.g. tariff restrictions. Such conditions must be checked by bank employees manually.

(4) The advising bank digitally forwards all documents to the issuing bank if the documents are considered correct.

(5) Else, the exporter has to resubmit the documents.

(6) Same as step (3) for issuing bank

(7) In case all conditions have been met, the documents are forwarded to the importer and

(8) the payment is triggered automatically by a notification message from a smart contract. 
(9) The importer receives the documents in digital form and can pick up the trading goods using a digital signature.

For the entire process, each action concerning the process status is stored in the Blockchain, i.e. each process participant signs and with that also approves the process progress using his private key $\left(\mathrm{DO}_{6}\right)$. This allows for a real-time process status accessible for all participants $\left(\mathrm{DO}_{4}\right)$ and for a complete process history $\left(D O_{5}\right)$. We will further address the design objectives $\left(\mathrm{DO}_{7}\right)-\left(\mathrm{DO}_{9}\right)$ in the discussion section.

\begin{tabular}{ccl}
\hline Conditions checked automatically \\
Status & Documents \\
\hline$\square$ & CORRECT SHIPPING DATE \\
0 & CORRECT PORT OF DESTINATION \\
\hline$\square$ & CORRECT PORT OF ARRIVAL \\
\hline$\square$ & AMPORTER CORRECT IN ALL DOCUMENTS \\
\hline$\square$ & AUTOMATICALLY CHECKED CONDITION \#7 \\
\hline$\square$ & AUTOMATICALLY CHECKED CONDITION \#8 \\
\hline$\square$ & & AUTOMATICALLY CHECKED CONDITION \#9 \\
\hline
\end{tabular}

\section{Figure 3. Exemplary conditions to be checked using smart contracts}

\section{Evaluation and discussion}

We summarize the evaluation of the BDW briefly for each area of improvement (AI) in Table 4. For each AI, we state a status: considerably improved (CI), partly improved (PI), unaltered (UA) or impaired $(I M P)$ for reasons of clarity and comprehensibility.

\section{Table 4. Areas of improvement - BDW} prototype

\begin{tabular}{|c|c|}
\hline $\begin{array}{l}\text { Area }\left(A I_{i}\right) \\
\text { and status of } \\
\text { improvement }\end{array}$ & Description and evaluation of BDW \\
\hline $\begin{array}{l}\boldsymbol{A I}_{\mathbf{1}}: \\
\text { Processing } \\
\text { medium } \\
\rightarrow C I\end{array}$ & $\begin{array}{l}\text { Digitized process: All relevant } \\
\text { process steps can be conducted in } \\
\text { digital form. Signatures can be } \\
\text { achieved using private keys. Thus, } \\
\text { neither multiple versions of } \\
\text { documents nor paper-based sending is } \\
\text { necessary anymore. }\end{array}$ \\
\hline $\begin{array}{l}\boldsymbol{A I}_{2}: \\
\text { Document } \\
\text { processing } \\
\rightarrow P I\end{array}$ & $\begin{array}{l}\text { Reduced manual effort: Parts of the } \\
\text { document auditing processes of both } \\
\text { banks can be conducted automatically } \\
\text { using smart contracts. However, } \\
\text { significant portions of the document }\end{array}$ \\
\hline
\end{tabular}

\begin{tabular}{|c|c|}
\hline & $\begin{array}{l}\text { checking still need manual effort as } \\
\text { they require experience and expertise. }\end{array}$ \\
\hline $\begin{array}{l}\mathrm{AI}_{3}: \\
\text { Processing } \\
\text { mode } \\
\rightarrow U A\end{array}$ & $\begin{array}{l}\text { Sequential but parallel possible: So } \\
\text { far, the implemented prototype is } \\
\text { sequential. However, the BDW } \\
\text { allows for parallel processing in case } \\
\text { this would be a desired property for } \\
\text { the process in the future. }\end{array}$ \\
\hline $\begin{array}{l}\mathrm{AI}_{4}: \\
\text { Process } \\
\text { tracking } \\
\rightarrow C I\end{array}$ & $\begin{array}{l}\text { Overall tracking system: An overall } \\
\text { tracking system is in place for the } \\
\text { BDW. With that, transparency of the } \\
\text { entire process is guaranteed. }\end{array}$ \\
\hline $\begin{array}{l}\mathrm{AI}_{5}: \\
\text { Process } \\
\text { history } \\
\rightarrow C I\end{array}$ & $\begin{array}{l}\text { Overall process history: All process } \\
\text { steps are recorded (time stamp, } \\
\text { action, etc.) such that each participant } \\
\text { has the full process overview. }\end{array}$ \\
\hline $\begin{array}{l}\boldsymbol{A I}_{\mathbf{6}}: \\
\text { Trust and } \\
\text { identification } \\
\rightarrow C I\end{array}$ & $\begin{array}{l}\text { Known process participants: All } \\
\text { participants are known to the system } \\
\text { as for the private Blockchain we } \\
\text { require pre-identification for } \\
\text { participation. For example, to get the } \\
\text { trading goods in the harbor, the } \\
\text { importer's representative can sign } \\
\text { using his private key. }\end{array}$ \\
\hline $\begin{array}{l}\mathrm{AI}_{7}: \\
\text { Process time } \\
\rightarrow C I\end{array}$ & $\begin{array}{l}\text { Overall time of a few hours }\left(D O_{7}\right) \text { : } \\
\text { As the lengthy sending process } \\
\text { disappears, manual auditing is } \\
\text { diminished and even parallel } \\
\text { processing is possible the process } \\
\text { time shortens heavily. }\end{array}$ \\
\hline $\begin{array}{l}\boldsymbol{A I}_{\mathbf{8}}: \\
\text { Process } \\
\text { flexibility } \\
\rightarrow \text { IMP }\end{array}$ & $\begin{array}{l}\text { Less flexible: Many process steps } \\
\text { must be standardized within the } \\
\text { BDW. Hence, this standardization } \\
\text { leads to less flexible process steps. } \\
\text { For example, exporter in developing } \\
\text { countries might not always have } \\
\text { access to the technology needed for } \\
\text { the BDW solution. }\end{array}$ \\
\hline $\begin{array}{l}\boldsymbol{A I}_{\mathbf{9}}: \text { Costs } \\
\rightarrow \text { Not clear }\end{array}$ & $\begin{array}{l}\text { Costs }\left(\mathrm{DO}_{9}\right) \text { : On the one hand, due to } \\
\text { a shorter process time and less } \\
\text { manual effort the cost of the pure } \\
\mathrm{BDW} \text { is decreased. On the other } \\
\text { hand, the Blockchain solution as an } \\
\text { IT system imposes new costs to the } \\
\text { participating parties. As of today, } \\
\text { there is no realistic estimation as of } \\
\text { what portion weighs more. However, } \\
\text { with increasing development of } \\
\text { Blockchain technology costs will } \\
\text { decrease as well. }\end{array}$ \\
\hline
\end{tabular}

To evaluate the areas of improvement, we conducted four semi-structured interviews listed in Table 1. All interviewees emphasized that Blockchain technology can play an important role for the financial services industry if standardization and applicability is developed further. Concerning the BDW, they all see a considerable improvement compared to the status quo. All interviewees value the improved efficiency of the BDW due to decreased process time and 
emphasize the advantages and possibilities in terms of auditability of a Blockchain solution. A tamper-proof, clear and easily accessible process history can be a major advantage regarding compliance and audit. It is common sense that the greatest obstacles are questions of process and document standardization.

In addition to the stated areas of improvement, we summarize the main statements of all interviewees. Interviewee \#1 pointed out that, though some features of the BDW could have been achieved using other (established) technologies, the major advantage lies in the decentralized nature and the trust achieved by a Blockchain solution. For a letter of credit as well as in general, it seems much more likely to accomplish cross-organizational WfMSs without having a central authority of trust. Interviewee \#2 especially values the automation of process steps, thus, sees potential for standardized processes and brings up the idea of combining the concept of smart contracts and artificial intelligence. Further, interviewee \#2 points out that a Blockchain solution could be a real alternative to existing WfMSs, though both concepts may face similar challenges. Both, interviewee \#3 and \#4 emphasize the importance of document standardization. As it can be the case that documents are needed from different sources (e.g. certificates from different certifying organizations), a standardization of these documents, ideally in digital form, is necessary. Interviewee \#3 explains that the BDW will only turn into a positive business case if many organizations worldwide participate. To be successful, a development of such an international WfMS could be pushed by major banks that are actively conducting international trade finance. Besides, interviewee \#3 sees the potential to transfer the concept of BDW to workflows like complaint processing or procurement processes. Further, Interviewee \#4 underlines that ease of use is important for acceptance of such a system.

Overall, the status quo of the process (DW) could be substantially improved. The improvements directly relate to two aspects of our prototype: process digitization and the properties of Blockchain. Unsurprisingly, some improvements could have been also achieved using other than Blockchain technology. However, the combination of decentralization and a tamper-proof process history that facilitates auditability are a major advantage of a Blockchain solution. First, decentralization can be a major advantage as it overcomes the question of trust provision within the system. This infrastructural property may even enable and enforce increased standardization. It is oftentimes argued that Blockchain technology can make intermediaries dispensable [8]. For the DW the two banks act as intermediaries in the processing of documents. But more importantly, the banks bear the credit risk. We leave the question how this topic could be addressed by Blockchain solutions for further research. Second, auditability is crucial for a documentary letter of credit. An exact history of the document process is necessary in case the trading goods turn out to be different from the description in the documents. We underline the importance of standardization regarding the process and the respective documents.

On the downside, using a cross-organizational WfMS may impair process flexibility. However, this is not a distinct property of a Blockchain solution but of any IT system used in such a context (interviewee \#2). Further, the automation of certain tasks using smart contracts is dependent on digital input and standardized forms which impairs applicability as long as overall standards are missing. Also, there are open questions regarding regulatory requirements that must be addressed.

\section{Conclusion and outlook}

We demonstrated how the status quo of a documentary letter of credit can be improved using Blockchain technology, implemented an according prototype, and evaluated the areas of improvement by comparing the status quo (DW) with the new process (BDW). We regard the insights transferable to other workflows, thus, our prototype provides an example how to design and implement a Blockchain solution in the field of BPM. In particular, we demonstrated that Blockchain technology can be an alternative solution for cross-organizational WfMSs. When standardization improves, many application areas for Blockchain in the field of BPM seem realistic, e.g. internal auditing processes, complaint processing, or diverse procurement processes. Particularly, a tamperproof transaction history can be a major improvement for many workflows across organizational boundaries.

Generally speaking, Blockchain has the potential to serve as an infrastructure for cross-organizational workflow management. Blockchain can fill empty space as a solution that does not require a central authority. In other words, WfMSs may be introduced between many organizations that have so far not been possible due to huge differences between them, high costs or previously unknown opportunities. For similar reasons, Blockchain solutions could also replace existing platforms. For our use case, we implemented a private Blockchain as a first step of research. However, in a productive system many parties are supposed to participate in the BDW. Thus, the question arises if a private Blockchain is still advised and who would maintain the system as well as access and rights management. Any provider of a Blockchain 
solution is somewhat counterintuitive to the basic property of Blockchain being a decentralized system without intermediaries. A public solution should be considered in future research, though a BDW solution should be permissioned, as the confirmation of process steps should only be possible for certain parties.

Our research is not without limitations. In certain areas, our Blockchain solution (BDW) faces the same challenges many IT systems are prone to. The entire document input is assumed to be in digital form. That is certainly possible, yet a challenge in real world scenarios, e.g. due to regulatory requirements (signature), missing technological possibilities (e.g. in developing countries) or missing standardization. The question how the digitization of required documents can be achieved, how the information of the documents is extracted, or to what extent standardized digital documents can be used, must be examined in more detail. However, standardization in terms of Blockchain technology itself as well as for the documents for a documentary letter of credit has not reached a level that enables productive utilization of a BDW. Yet, the prevalence of a new technological possibility to improve existing workflows may facilitate increased standardization. Our prototype does not address all aspects necessary for a productive system in full detail. For instance, how the exchange of keys between process participants can be conducted still needs to be addressed. Although we implemented the entire workflow for a letter of credit, we have so far only tested it in collaboration with one process participant (issuing bank) and simulated the other process participants. The next step of research should include other participants in real world testing.

Future research opportunities arise in various ways. Of course, Blockchain applications in the field of BPM need further testing, particularly in real world applications. A classification scheme or taxonomy for Blockchain use cases in BPM or cross-organizational workflows in particular could be a starting point for further research in the field. As intermediaries in Blockchain ecosystems can potentially be replaced [8], the further development of this use case (a documentary letter of credit) without intermediaries is a logical next step for further research. Specifically, the question who would develop and maintain Blockchain systems in cross-organizational settings must be addressed. Also, distinct risk, benefit, or cost considerations of Blockchain solutions do not yet exist and leave room for practically relevant research.

\section{References}

[1] Beck, R. and C. Müller-Bloch, "Blockchain as Radical Innovation: A Framework for Engaging with Distributed
Ledgers as Incumbent Organization", $50^{\text {th }}$ Hawaii International Conference on System Sciences (HICSS 2017). Waikoloa, Hawaii, USA, 2017.

[2] Beck, R., J. Stenum Czepluch, N. Lollike, and S. Malone, "Blockchain - The Gateway to Trust - free Cryptographic Transactions", $24^{\text {th }}$ European Conference on Information Systems (ECIS). Istanbul, Turkey, 2016.

[3] Beck, R., S. Weber, and R.W. Gregory, "Theorygenerating design science research", Information Systems Frontiers, 15(4), 2013, pp. 637-651.

[4] Christidis, K. and M. Devetsikiotis, "Blockchains and Smart Contracts for the Internet of Things", IEEE Access, 4, 2016, pp. 2292-2303.

[5] Croman, K., C. Decker, I. Eyal, A.E. Gencer, A. Juels, A. Kosba, A. Miller, P. Saxena, E. Shi, E. Gün Sirer, D. Song, and R. Wattenhofer, "On Scaling Decentralized Blockchains", in Financial Cryptography and Data Security, J. Clark, S. Meiklejohn, P.Y.A. Ryan, D. Wallach, M. Brenner, and K. Rohloff, Editors. 2016. Springer: Berlin, Heidelberg.

[6] Dorri, A., S.S. Kanhere, R. Jurdak, and P. Gauravaram, "Blockchain for IoT security and privacy: The case study of a smart home", in 2017 IEEE International Conference on Pervasive Computing and Communications Workshops (PerCom Workshops), Kona, Big Island, Hawaii, USA.

[7] Fanning, K. and D.P. Centers, "Blockchain and Its Coming Impact on Financial Services", Journal of Corporate Accounting \& Finance, 27(5), 2016, pp. 53-57.

[8] Glaser, F., "Pervasive Decentralisation of Digital Infrastructures: A Framework for Blockchain enabled System and Use Case Analysis", 50 ${ }^{\text {th }}$ Hawaii International Conference on System Sciences (HICSS 2017). Waikoloa, Hawaii, USA, 2017.

[9] Glaser, F. and L. Bezzenberger, "Beyond Cryptocurrencies - A Taxonomy of Decentralized Consensus Systems", $23^{\text {rd }}$ European Conference on Information Systems (ECIS). Münster, Germany, 2015.

[10] Grassi, P.S., "Letter of credit transactions: the Banks' position in determining documentary compliance. A comparative evaluation under U.S., Swiss and German law”, Pace international law review, 1995.

[11] Hevner, A. and S. Chatterjee, Design Research in Information Systems: Theory and Practice, Springer, New York, 2010.

[12] Hevner, A.R., S.T. March, J. Park, and S. Ram, "Design Science in Information Systems Research", MIS QUARTERLY, 28(1), 2004, pp. 75-105.

[13] Jie Meng, S.Y.W. Su, H. Lam, and A. Helal, "Achieving dynamic inter-organizational workflow management by integrating business processes, events and rules", $35^{\text {th }}$ Hawaii International Conference on System Sciences (HICSS 2002). Hawaii, USA, 2002.

[14] Korpela, K., J. Hallikas, and T. Dahlberg, "Digital Supply Chain Transformation toward Blockchain 
Integration", 50 $0^{\text {th }}$ Hawaii International Conference on System Sciences (HICSS 2017). Hawaii, USA, 2017.

[15] Kumar, A. and J. Leon Zhao, "Workflow support for electronic commerce applications", Decision support systems, 32(3), 2002, pp. 265-278.

[16] March, S.T. and G.F. Smith, "Design and Natural Science Research on Information Technology", Decision support systems, 15(4), 1995, pp. 251-266.

[17] March, S.T. and V.C. Storey, "Design science in the information systems discipline: an introduction to the special issue on design science research", MIS QUARTERLY, 32(4), 2008, pp. 725-730.

[18] Mattila, J., The Blockchain Phenomenon - The Disruptive Potential of Distributed Consensus Architectures, The Research Institute of the Finnish Economy, 2016.

[19] Mendling, J., I. Weber, W. van der Aalst, J. Vom Brocke, C. Cabanillas, F. Daniel, S. Debois, C. Di Ciccio, M. Dumas, S. Dustdar, A. Gal, L. García-Banuelos, G. Governatori, R. Hull, M. La Rosa, H. Leopold, F. Leymann, J. Recker, M. Reichert, H.A. Reijers, S. Rinderle-Ma, A. Rogge-Solti, M. Rosemann, S. Schulte, M.P. Singh, T. Slaatsq, M. Staples, B. Weber, M. Weidlich, M. Wesket, X. Xu, and L. Zhu, "Challenges and Opportunities of using Blockchains for Business Process Management", 2017.

[20] Milani, F.P., L. García-Bañuelos, and M. Dumas, Blockchain and Business Process Improvement, 2016.

[21] Munsing, E., J. Mather, and S. Moura, "Blockchains for Decentralized Optimization of Energy Resources in Microgrid Networks.", 2017.

[22] Myers, M.D. and M. Newman, "The qualitative interview in IS research: Examining the craft", Information and Organization, 17(1), 2007, pp. 2-26.

[23] Nakamoto, S., Bitcoin: A Peer-to-Peer Electronic Cash System, 2008.

[24] Nofer, M., P. Gomber, O. Hinz, and D. Schiereck, "Blockchain", Business \& Information Systems Engineering, 59(3), 2017, pp. 183-187.

[25] Nunamaker Jr, J.F., M. Chen, and T.D.M. Purdin, "Systems Development in Information Systems Research", Journal of management information systems, 7(3), 1990, pp. 89-106.

[26] Peffers, K., T. Tuunanen, M.A. Rothenberger, and S. Chatterjee, "A Design Science Research Methodology for Information Systems Research", Journal of management information systems, 24(3), 2007, pp. 45-77.

[27] Ping Jiang, Xinyu Shao, Haobo Qiu, and Peigen Li, "Interoperability of Cross-organizational Workflows based on Process-view for Collaborative Product Development", Concurrent Engineering, 16(1), 2008, pp. 73-87.

[28] Porru, S., A. Pinna, M. Marchesi, and R. Tonelli, "Blockchain-Oriented Software Engineering: Challenges and New Directions", $39^{\text {th }}$ International Conference on Software Engineering Companion, 2017, pp. 169-171.

[29] Reijers, H.A., I. Vanderfeesten, and W.M.P. van der Aalst, "The effectiveness of workflow management systems: A longitudinal study", International Journal of Information Management, 36(1), 2016, pp. 126-141.

[30] Rimba, P., A.B. Tran, I. Weber, M. Staples, A. Ponomarev, and X. Xu, "Comparing Blockchain and Cloud Services for Business Process Execution", 2017 IEEE International Conference on Software Architecture (ICSA), 2017, pp. 257-260.

[31] Schulz, K.A. and M.E. Orlowska, "Facilitating crossorganisational workflows with a workflow view approach", Data \& Knowledge Engineering, 51(1), 2004, pp. 109-147.

[32] Stohr, E.A. and J.L. Zhao, "Workflow Automation: Overview and Research Issues", Information Systems Frontiers, 3(3), 2001, pp. 281-296.

[33] Swan, M., Blockchain: Blueprint for an New Economy, $1^{\text {st }}$ edn., O’Reilly Media, Inc., Sebastopol, 2015.

[34] van der Aalst, W., "Loosely coupled interorganizational workflows", Information \& Management, 37(2), 2000, pp. 67-75.

[35] van der Aalst, W.M.P., "The Application of Petri Nets in Workflow Management", Journal of Circuits, Systems and Computers, 08(01), 1998, pp. 21-66.

[36] Walls, J.G., G.R. Widmeyer, and O.A. El Sawy, "Building an Information System Design Theory for Vigilant EIS”, Information Systems Research, 3(1), 1992, pp. 36-59.

[37] Weber, I., X. Xu, R. Riveret, G. Governatori, A. Ponomarev, and J. Mendling, "Untrusted Business Process Monitoring and Execution Using Blockchain.”, Springer, Cham, 9850, 2016.

[38] Wood, G., "Ethereum: A Secure Decentralised Generalised Transaction Ledger", Ethereum Project Yellow Paper, 151, 2014.

[39] Xu, L., H. Liu, S. Wang, and K. Wang, "Modelling and analysis techniques for cross-organizational workflow systems", Systems Research and Behavioral Science, 26(3), 2009, pp. 367-389.

[40] Yli-Huumo, J., D. Ko, S. Choi, S. Park, and K. Smolander, "Where Is Current Research on Blockchain Technology?-A Systematic Review", PloS one, 11(10), 2016, pp. e0163477.

[41] Zeng, Q., S.X. Sun, H. Duan, C. Liu, and H. Wang, "Cross-organizational collaborative workflow mining from a multi-source log", Decision support systems, 54(3), 2013, pp. 1280-1301.

[42] Ziemann, J., T. Matheis, and J. Freiheit, "Modelling of Cross-Organizational Business Processes - Current Methods and Standards", 2015. 